\title{
Molecular analysis and distribution of multidrug-resistant Enterococcus faecium isolates belonging to clonal complex 17 in a tertiary care center in Mexico City
}

Sara A Ochoa', Gerardo Escalona', Ariadnna Cruz-Córdova', Leticia B Dávila', Zeus Saldaña', Vicenta Cázares-Domímguez ${ }^{1}$, Carlos A Eslava², Briceida López-Martínez³, Rigoberto Hernández-Castro ${ }^{4}$, Guillermo Aquino-Jarquin ${ }^{5}$ and Juan Xicohtencatl-Cortes ${ }^{1 *}$

\begin{abstract}
Background: Enterococcus faecium has recently emerged as a multidrug-resistant nosocomial pathogen involved in outbreaks worldwide. A high rate of resistance to different antibiotics has been associated with virulent clonal complex 17 isolates carrying the esp and hyl genes and the purk1 allele.

Results: Twelve clinical vancomycin-resistant Enterococcus faecium (VREF) isolates were obtained from pediatric patients at the Hospital Infantil de México Federico Gómez (HIMFG). Among these VREF isolates, 58.3\% (7/12) were recovered from urine, while $41.7 \%$ (5/12) were recovered from the bloodstream. The VREF isolates showed a 100\% rate of resistance to ampicillin, amoxicillin-clavulanate, ciprofloxacin, clindamycin, chloramphenicol, streptomycin, gentamicin, rifampicin, erythromycin and teicoplanin. In addition, $16.7 \%(2 / 12)$ of the isolates were resistant to linezolid, and $66.7 \%(8 / 12)$ were resistant to tetracycline and doxycycline. PCR analysis revealed the presence of the vanA gene in all 12 VREF isolates, esp in 83.3\% (10/12) of the isolates and hyl in 50\% (6/12) of the isolates. Phylogenetic analysis via molecular typing was performed using pulsed-field gel electrophoresis (PFGE) and demonstrated 44\% similarity among the VREF isolates. MLST analysis identified four different sequence types (ST412, ST757, ST203 and ST612).

Conclusion: This study provides the first report of multidrug-resistant VREF isolates belonging to clonal complex 17 from a tertiary care center in Mexico City. Multidrug resistance and genetic determinants of virulence confer advantages among VREF in the colonization of their host. Therefore, the prevention and control of the spread of nosocomial infections caused by VREF is crucial for identifying new emergent subclones that could be challenging to treat in subsequent years.
\end{abstract}

Keywords: Enterococcus faecium, Multidrug-resistant, Clonal complex, Pulsotypes, Virulence

\footnotetext{
* Correspondence: juanxico@yahoo.com

'Departamento de Infectología, Laboratorio de Bacteriología Intestinal,

Hospital Infantil de México Federico Gómez, México City, DF 06720, México

Full list of author information is available at the end of the article
} 


\section{Background}

Enterococci are opportunistic pathogens of the normal intestinal microbiota of humans and animals [1,2]. The most common species of Enterococcus involved in nosocomial infections is Enterococcus faecium (E. faecium) [1,2]. This pathogen is associated with hospitalacquired infections such as UTIs (urinary tract infections), wounds, bacteremia, endocarditis and meningitis [1,2].

In recent years, the emergence of multidrug-resistant E. faecium has increased [3-5]. The recommended treatment for Enterococcus infections has been penicillin alone or combined with aminoglycosides. However, due to increased resistance to aminoglycosides, vancomycin is currently the antibiotic employed to treat these infections. In the last several decades, the number of vancomycin-resistant enterococci (VRE) has increased. The first VRE isolates were reported in the United Kingdom in the late 1980s [6]. In the United States, more than $80 \%$ of $E$. faecium isolates from hospitals are now resistant to vancomycin, and virtually all of them (>90\%) exhibit ampicillin resistance [7]. Vancomycin-resistant Enterococcus faecium (VREF) has been associated with outbreaks in hospitals worldwide [2]. The rates of VREF colonization and infection have risen steadily, with most cases being caused by strains displaying glycopeptide resistance to VanA and VanB [8-11].

In addition to multidrug resistance, E. faecium produces diverse factors that contribute to its pathogenesis, including virulence molecules such as secreted antigen SagA [12], cell wall-anchored collagen adhesin (Acm) [13], hyaluronidase (Hyl) [14] and enterococcal surface protein (Esp) [15]. However, the traits that contribute to the transition of E. faecium from a commensal to a nosocomial pathogen have not been identified [16].

Molecular typing methods are essential for identifying hospital-associated outbreaks of E. faecium. Multilocus sequence typing (MLST) has revealed the existence of host-specific genogroups, including a specific genetic lineage designated clonal complex 17, associated with hospital-related isolates [1,17]. MLST of E. faecium is based on identifying alleles from DNA sequences in internal fragments of housekeeping genes $(\operatorname{atp} A, d d l, g d h$, purK, gyd, pstS and $a d k$ ), resulting in a numeric allelic profile, with each profile then being assigned a sequence type (ST) [17].

Complex 17 most likely evolved from the primary E. faecium ancestor ST-22, while ST-17 represents an important secondary founder with additional linages designated to complex 17 [18]. Clonal complex 17 is characterized by ampicillin and quinolone resistance and the presence of a putative pathogenicity island that includes the esp and/or hyl genes in the majority of isolates $[1,18-20]$. Various STs belonging to clonal complex 17, such as ST16, ST17, ST18, ST203 and ST412, are currently being disseminated worldwide [21,22]. Interestingly, half of the STs within the clonal complex 17 polyclonal subpopulation have also been identified in samples obtained from healthy humans, swine, poultry and pets [16].

In Mexico, there is little available information about the prevalence of VREF isolates, and no study related to clonal complex 17 has been performed in pediatric patients. The aim of this study was to genotypically and phenotypically characterize VREF clinical isolates from 12 immunocompromised pediatric patients at the Hospital Infantil de México Federico Gómez (HIMFG). This study involved amplification of the resistance genes $v a n A$ and $v a n B$ and two virulence genes (esp and $h y l$ ) and molecular typing via pulsed-field gel electrophoresis (PFGE) and MLST.

\section{Methods}

\section{Bacterial isolates}

Twelve E. faecium isolates of clinical importance were obtained from 12 patients with nosocomial infections in the PICU (Pediatric Intensive Care Unit), oncology, gastroenterology and transplant wards of HIMFG during the period from July 2009 to April 2011. The isolates were maintained at $-70^{\circ} \mathrm{C}$ in skim milk (Becton Dickinson, New Jersey, USA) and cultured on 5\% sheep blood agar plates (Becton Dickinson, New Jersey, USA) at $37^{\circ} \mathrm{C}$ under $5 \% \mathrm{CO}_{2}$ for $24 \mathrm{~h}$. The E. faecalis $\mathrm{ATCC}^{\circ}$ 29212, E. faecalis ATCC 51299 and E. faecium ATCC ${ }^{\circ}$ 51559 strains (American Type Culture Collection Manassas, VA, USA) were used as controls.

\section{Biochemical tests}

Bacteria were grown on blood agar, and identification was performed using manual methods. All colonies were grown in brain heart infusion broth (BHI) (Becton Dickinson, New Jersey, USA) with $6.5 \% \mathrm{NaCl}$ and on bile esculin agar (Oxoid Sunnyvale, California, USA) to determine their hydrolysis grade. Disks impregnated with the substrate L-pyrrolidonyl-beta-naphthylamide were used to perform pyrrolidonase tests (Oxoid Biochemical Identification System, Oxoid LTD., Basingstoke, Hampshire, England). Reduction of tellurite (Merck, Darmstadt, Germany) was evaluated via growing the bacteria on $0.04 \%$ potassium tellurite.

\section{Antibiotic susceptibility}

The antibiotic susceptibility profiles of the 12 VREF isolates were determined via the minimum inhibitory concentration (MIC) technique by means of the microdilution method using Mueller-Hinton broth (MHB), as recommended by the Clinical and Laboratory Standards Institute. MIC tests were performed for vancomycin (MP Biomedicals, Solon, Ohio, USA), 
teicoplanin (Sigma-Aldrich, St. oLouis, Missouri, USA), chloramphenicol (MP Biomedicals, Solon, Ohio, USA), ciprofloxacin (MP Biomedicals, Solon, Ohio, USA), streptomycin (Alexis Biochemical, San Diego California, USA), linezolid (Sigma-Aldrich, St. Louis, Missouri, USA), rifampicin (MP, Biomedicals, Ohio, USA), nitrofurantoin (MP Biomedicals, Solon, Ohio, USA), tetracycline (MP Biomedicals, Solon, Ohio, USA), doxycycline (Sigma-Aldrich, St. Louis, Missouri, USA), erythromycin (MP Biomedicals, Solon, Ohio, USA), tigecycline (Sigma-Aldrich, St. Louis, Missouri, USA), gentamicin (MP Biomedicals, Solon, Ohio, USA) and amoxicillinclavulanate (Glaxo-Smith-Kline, Philadelphia, Pennsylvania, USA). Several concentrations $(256-0.625 \mu \mathrm{g} / \mathrm{ml})$ of the antibiotics were tested in Mueller Hinton broth, with $100 \mu \mathrm{l}$ of those dilutions being loaded into each well of a microplate. For each dilution, $100 \mu \mathrm{l}$ of a bacterial suspension $\left(1.5 \times 10^{8} \mathrm{CFU} / \mathrm{ml}\right)$ was inoculated and grown overnight at $37^{\circ} \mathrm{C}$ under a $\mathrm{CO}_{2}$ atmosphere. After bacterial growth was detected, the MIC for each isolate of E. faecium was reported as the highest concentration $(\mu \mathrm{g} / \mathrm{ml})$ of antibiotics in which no growth was observed. The E. faecalis ATCC 29212 strain (American Type Culture Collection Manassas, VA, USA) was used as a control. These isolates were also evaluated for high-level aminoglycoside resistance (HLAR) to streptomycin $(1,000 \mu \mathrm{g} / \mathrm{ml})$ and gentamicin $(500 \mu \mathrm{g} / \mathrm{ml})$.

\section{Detection of the glycopeptide resistance genes vanA and vanB}

PCR was performed to detect the glycopeptide resistance genes vanA and $\operatorname{vanB}$ in the 12 E. faecium clinical isolates using specific primers (Table 1) [23]. Briefly, genomic DNA was purified using the Wizard Genomic DNA Purification Kit (Promega Madison, Wisconsin, USA) from a bacterial culture grown in BHI broth incubated at $37^{\circ} \mathrm{C}$ for $24 \mathrm{~h}$. The amplification reactions were prepared in a final volume of $50 \mu \mathrm{l}$, as follows: $25 \mu \mathrm{l}$ of amplification mix $(22 \mathrm{mM}$ Tris/HCl, $\mathrm{pH}$ 8.4; $55 \mathrm{mM}$ $\mathrm{KCl} ; 1.65 \mathrm{mM} \mathrm{MgCl}_{2} ; 25 \mu \mathrm{M}$ each dNTP; $0.6 \mathrm{U}$ recombinant Taq DNA polymerase $/ \mathrm{ml}), 100 \mathrm{ng} / \mu \mathrm{l}$ of bacterial
DNA, $10 \mu \mathrm{l}$ of $\mathrm{H}_{2} \mathrm{O}$ and $5 \mu \mathrm{l}$ of primer solution $(10 \mathrm{pg} /$ $\mu \mathrm{l})$. A Perkin Elmer 9600 thermocycler was programmed to run for 30 cycles with the following parameters: denaturing at $94^{\circ} \mathrm{C}$ for $3 \mathrm{~m}$, annealing at $55^{\circ} \mathrm{C}$ for $45 \mathrm{~s}$ and extension at $72^{\circ} \mathrm{C}$ for $1 \mathrm{~m}$, with a final extension at $72^{\circ} \mathrm{C}$ for $2 \mathrm{~m}$. The samples were analyzed via electrophoresis in 1\% agarose gels (Agarose LE, Promega) using a 100 bp DNA ladder (Gibco/BRL Life Technologies, Breda, The Netherlands). E. faecium strain ATCC 51559 $\left(v_{a n A^{+}}\right)$and E. faecalis strain ATCC $51299\left(\right.$ vanB $\left.^{+}\right)$ were used as controls in the PCR experiments [24].

\section{PCR screening for the esp and hyl genes}

DNA from bacterial cultures was extracted and amplified via PCR using primers for the $e s p_{E f m}$ and $h y l_{E f m}$ genes (Table 1), generating bands of $954 \mathrm{bp}$ and $661 \mathrm{bp}$, respectively $[14,25]$.

\section{Molecular typing of VREF}

PFGE of the 12 VREF clinical isolates was carried out following the protocols of Morrison et al. [26,27]. Briefly, the samples were digested with $50 \mathrm{U}$ of SmaI (New England Biolab, Ipswich, MA, USA) for $4 \mathrm{~h}$ at $25^{\circ} \mathrm{C}$. The digested plugs were separated via electrophoresis in $1 \%$ agarose gels (BioRad, Hercules, California, USA) using ultra-pure DNA agarose (BioRad, Hercules, California, USA), with $0.5 \mathrm{X} \mathrm{TBE}$ as the running buffer in the CHEF MAPPER system (BioRad Laboratories, Hercules, California, USA), run at $6 \mathrm{~V} / \mathrm{cm}$ at $14^{\circ} \mathrm{C}$ under two different linear ramped pulse times: 1 to $10 \mathrm{~s}$ for $16 \mathrm{~h}$ and 10 to $40 \mathrm{~s}$ for $22 \mathrm{~h}$. A PFGE lambda ladder (New England Biolabs, Hertfordshire, England, UK) was used as a molecular weight marker, and the gels were stained for $40 \mathrm{~m}$ with $0.5 \mathrm{mg} / \mathrm{ml}$ of ethidium bromide for visualization under UV light. The obtained banding patterns were initially interpreted via visual inspection according to the criteria specified by Tenover et al. [28]. Cluster analysis was performed with BioNumerics (Applied Maths, Inc., Austin, TX, USA) using the DICE correlation coefficient and the unweighted pair group

Table 1 Primers sequences used in this study

\begin{tabular}{|c|c|c|c|c|}
\hline Gene & Primer & Sequence $\left(5^{\prime}\right.$ to $\left.3^{\prime}\right)$ & Size (bp) & Reference \\
\hline \multirow[t]{2}{*}{ vanA } & vanA-F & CATGAATAGAATAAAAGTTGCAATA & 1,030 & (Clark et al., 1993) [23] \\
\hline & $\operatorname{van} A-R$ & CCCCTTTAACGCTAATACGATCAA & & \\
\hline \multirow[t]{2}{*}{ vanB } & $\operatorname{vanB}-\mathrm{F}$ & GTCACAAACCGGAGGCGAGGA & 433 & (Clark et al., 1993) [23] \\
\hline & vanB-R & CCGCCATCCTCCTGCAAAAAA & & \\
\hline \multirow[t]{2}{*}{$e s p_{E f m}$} & esp-F & TTGCTAATGCTAGTCCACGACC & 945 & (Shankar et al., 1999) [25] \\
\hline & esp-R & GCGTCAACACTTGCATTGCCGA & & \\
\hline \multirow[t]{2}{*}{ hyl $\left.\right|_{E f m}$} & hyl-F & GAGTAGAGGAATATCTTAGC & 661 & (Rice et al., 2003) [14] \\
\hline & hyl-R & AGGCTCCAATTCTGT & & \\
\hline
\end{tabular}


mathematical average algorithm (UPGMA) as the grouping method [29].

The PFGE pulsotypes of the 12 VREF clinical isolates were also genotyped through multilocus sequence typing (MLST) according to a standard protocol described by Homan et al. [17]. Fragments of seven housekeeping genes (atpA, $d d l, g d h, p u r K$, gyd, pstS and $a d k$ ) were sequenced using a 3730xl DNA Analyzer (Applied Biosystems, Foster City, California, USA), thus obtaining their allelic profiles, and the STs for each unique allelic profile were designated on the basis of information from the MLST website (http://efaecium.mlst.net).

\section{Results}

\section{Origin of the strains}

A total of 12 VREF clinical isolates obtained during the period from July 2009 to April 2011 were included in this study. The risk factors of the 12 patients were characterized by a minimum hospital stay of 4 days, assistance in the PICU and treatment with vancomycin. During their stay, the 12 patients were subjected to surgical procedures and received a central venous catheter, steroids and immunosuppressive treatment. Among the VREF isolates, 58.3\% (7/12) were obtained from urine, while $41.6 \%(5 / 12)$ were obtained from the bloodstream. The VREF isolates were obtained from patients with different pathologies (Table 2).

\section{Detection of susceptibility patterns and glycopeptide resistance in the VREF isolates}

The results obtained for the 12 VREF clinical isolates showed a $100 \%$ rate of resistance to ampicillin, amoxicillin-clavulanate, ciprofloxacin, clindamycin, chlorampheni col, streptomycin, gentamicin, rifampicin, erythromycin and teicoplanin. The MIC values for each VREF isolate are presented in Table 3. In addition, 16.7\% (2/12) of the VREF clinical isolates were resistant to linezolid, and $67 \%(8 / 12)$ were resistant to tetracycline and doxycycline (Table 3). However, all of the VREF isolates were susceptible to nitrofurantoin and tigecycline (Table 3). The HLAR values for gentamicin $(500 \mu \mathrm{g} / \mathrm{ml})$, streptomycin $(1,000 \mu \mathrm{g} / \mathrm{ml})$ and gentamicin/streptomycin (500/ $1,000 \mu \mathrm{g} / \mathrm{ml}$ ) were determined with to $50 \%(6 / 12), 25 \%$ $(3 / 12)$ and $25 \%(3 / 12)$, respectively.

The vanA and $v a n B$ genes of the 12 VREF clinical isolates were amplified via PCR. Interestingly, only the vanA gene was detected in all the VREF clinical isolates, as a 1,030 bp amplicon (data not shown), whereas the $v a n B$ gene, with a length of $433 \mathrm{bp}$, was not identified in the isolates (data not shown). The E. faecium ATCC $^{\circ} 51559\left(\right.$ vanA $\left.^{+}\right)$and E. faecalis ATCC 51299 $\left(\right.$ vanB $\left.^{+}\right)$strains were used as positive controls in the PCR assays [24].

\section{Prevalence of the esp and hyl virulence genes in the VREF isolates}

The esp and $h y l$ virulence genes, which are associated with a clonal subcluster known as clonal complex 17 in VREF clinical isolates, were detected via PCR. The esp and hyl genes were highly prevalent in the isolates. The esp virulence gene was detected in $83.3 \%$ $(10 / 12)$ of the isolates, and the $h y l$ virulence gene was present in $50 \%(6 / 12)$ of them. Therefore, three genotypes were determined for the VREF clinical isolates: $e s p^{+} / h y l^{-}$, $e s p^{+} / h y l^{+}$and $e s p^{-} / h y l^{+}$, at prevalence rates of $50 \%(6 / 12), 33.3 \%(4 / 12)$ and $16.7 \%(2 / 12)$, respectively.

Table 2 Characteristics of the 12 VREF isolates related to the patients' clinical diagnosis, source of clinical samples, ward, PFGE, sequence type and clonal complex

\begin{tabular}{|c|c|c|c|c|c|c|}
\hline Clinical isolate & Clinical diagnosis & Sources of clinical samples & Wards & PFGE & MLST/STs & $\overline{C C}$ \\
\hline $133 \mathrm{H}$ & Acute lymphocytic leukemia L1, fever, and neutropenia & Bloodstream & ONC & A & 757 & \\
\hline $926 U$ & Aplastic anemia, neutropenic colitis, septic shock & Urine & ONC & A & 203 & 17 \\
\hline $821 \mathrm{U}$ & Lupus erythematosus, septic Shock & Urine & TRPU & A & 412 & 17 \\
\hline $851 \mathrm{H}$ & Anaplastic lymphoma, tumor lysis syndrome, sepsis & Bloodstream & $\mathrm{PICU}$ & B & 757 & \\
\hline $215 \mathrm{H}$ & Venous catheter infection, Down syndrome & Bloodstream & $\mathrm{PICU}$ & $\mathrm{B}$ & 612 & 17 \\
\hline $222 \mathrm{U}$ & Acute myeloid leukemia M2, tumor lysis syndrome, Septic shock & Urine & ONC & B & 412 & 17 \\
\hline $127 \cup$ & Acute lymphocytic leukemia L1, fever, and neutropenia. & Urine & $\mathrm{PICU}$ & B1 & 412 & 17 \\
\hline $30 \mathrm{H}$ & Wilms tumor & Bloodstream & $\mathrm{PICU}$ & B1 & 412 & 17 \\
\hline $634 U$ & Septic shock, hemophagocytic lymphohistiocytosis & Urine & ONC & C & 757 & \\
\hline $459 U$ & Lupus erythematosus, sacroiliac ulcers & Urine & $\mathrm{PICU}$ & C & 412 & 17 \\
\hline $422 \mathrm{H}$ & Acute myeloid leukemia M4, fever, and neutropenia & Bloodstream & SS & D & 412 & 17 \\
\hline $155 U$ & cholestatic syndrome, choledochal cyst. & Urine & GST & $\mathrm{D}$ & 203 & 17 \\
\hline
\end{tabular}


Table 3 Minimum Inhibitory Concentration (MIC) to 12 clinical isolates of multidrug-resistant Enterococcus faecium

\begin{tabular}{|c|c|c|c|c|c|c|c|c|c|c|c|c|c|c|c|c|}
\hline \multirow{2}{*}{$\begin{array}{l}\text { Clinical } \\
\text { isolate }\end{array}$} & \multicolumn{16}{|c|}{ Antibiotics (MIC $\mu \mathrm{g} / \mathrm{ml}$ ) } \\
\hline & $\mathrm{Am}$ & Amc & CIP & $\mathrm{CC}$ & $\mathrm{C}$ & GM & $S$ & RA & $E$ & $\mathrm{Va}$ & TEI & Te & D & LZN & $\mathrm{F} / \mathrm{M}$ & TGC \\
\hline $133 \mathrm{H}$ & 128 & 128 & 512 & 128 & 64 & 32 & 512 & 4 & 32 & 512 & 16 & 1 & 1 & 1 & 8 & 2 \\
\hline $926 U$ & 256 & 256 & 4 & 128 & 32 & 32 & 64 & 4 & 32 & 512 & 32 & 64 & 8 & 2 & 2 & 2 \\
\hline $821 \cup$ & 128 & 128 & 256 & 256 & 32 & 32 & 32 & 32 & 32 & 256 & 128 & 64 & 64 & 2 & 16 & 1 \\
\hline $851 \mathrm{H}$ & 128 & 128 & 512 & 256 & 32 & 32 & $\geq 512$ & 4 & 32 & 512 & 16 & 2 & 1 & 4 & 16 & 2 \\
\hline $215 \mathrm{H}$ & 128 & 128 & 512 & 256 & 32 & 32 & $\geq 512$ & 4 & 32 & 512 & 16 & 2 & 0.25 & 1 & 4 & 1 \\
\hline $222 \mathrm{U}$ & 64 & 128 & 256 & 256 & 32 & 32 & 32 & 16 & 32 & 256 & 32 & 64 & 16 & 2 & 32 & 1 \\
\hline $127 \mathrm{U}$ & 128 & 128 & 256 & 256 & 32 & 32 & 32 & 32 & 32 & 256 & 64 & 64 & 16 & 8 & 32 & 2 \\
\hline $30 \mathrm{H}$ & 128 & 128 & 256 & 256 & 32 & 32 & 32 & 16 & 32 & 256 & 256 & 64 & 16 & 1 & 16 & 2 \\
\hline $634 \mathrm{U}$ & 64 & 64 & 256 & 256 & 32 & 32 & $\geq 512$ & 4 & 32 & 256 & 16 & 4 & 0.5 & 2 & 8 & 2 \\
\hline $459 \mathrm{U}$ & 256 & 256 & 256 & 256 & 64 & 32 & 32 & 16 & 32 & 256 & 32 & 64 & 16 & 2 & 16 & 1 \\
\hline $422 \mathrm{H}$ & 128 & 128 & 256 & 256 & 32 & 32 & 32 & 8 & 32 & 256 & 64 & 64 & 8 & 2 & 16 & 1 \\
\hline $155 \mathrm{U}$ & 128 & 128 & 256 & 256 & 32 & 32 & 128 & 8 & 32 & 256 & 64 & 64 & 16 & 2 & 16 & 2 \\
\hline $\mathrm{CVR}^{*}$ & $\geq 16$ & $\geq 8$ & $\geq 4$ & $\geq 4$ & $\geq 32$ & $\geq 16$ & $\geq 16$ & $\geq 4$ & $\geq 8$ & $\geq 32$ & $\geq 16$ & $\geq 16$ & $\geq 8$ & $\geq 4$ & $\geq 128$ & $\geq 16$ \\
\hline$\%$ R & 100 & 100 & 100 & 100 & 100 & 100 & 100 & 100 & 100 & 100 & 100 & 67 & 67 & 16.7 & 0 & 0 \\
\hline
\end{tabular}

Ampicillin (Am), amoxacillin/clavulanate (Amc), ciprofloxacin (CIP), clindamycin (CC), chloramphenicol (C), gentamicin (GM), streptomycin (S), rifampin (RA), erythromycin (E), vancomycin (Va), teicoplanin (TEl), tetracycline (Te), doxycycline (D), linezolid (LZN), nitrofurantoin (F/M), and tigecycline (TGC), ${ }^{*}$ Cut-off values for resistance to $\mathrm{MIC}(\mu \mathrm{g} / \mathrm{ml})$, Percentage of resistant $(\% \mathrm{R})$.

\section{Molecular typing analysis of the E. faecium isolates via PFGE and MLST}

The VREF isolates were analyzed via PFGE following SmaI digestion of genomic DNA. Data obtained through PFGE were analyzed using a dendrogram profile, which included the PFGE pulsotypes obtained from VREF (Figure 1). A total of four clusters (I-IV) with five DNA pulsotypes were identified, showing patterns consisting of 12 to 20 DNA fragments ranging in size from 48.5 to $339.5 \mathrm{~Kb}$ (Figure 1). Interestingly, 25\% (3/12) of the VREF clinical isolates observed via PFGE were categorized as pulsotype B and $16.7 \%(2 / 12)$ as pulsotype B1, with $92 \%$ genetic similarity being observed among these isolates (Figure 1). Meanwhile, 25\% (3/12) of the VREF isolates were classified as pulsotype A, showing a different pattern from pulsotypes B, C and D (Figure 1). However, $16.7 \%(2 / 12)$ of the VREF isolates were classified as pulsotypes $\mathrm{C}$ and $\mathrm{D}$, which displayed $50 \%$ genetic similarity. In addition, a maximum of $44 \%$ similarity was observed among all clusters of VREF isolates.

In this study, 12 VREF clinical isolates were subjected to MLST genotyping. Six of the 12 VREF isolates (50\%) belonged to ST412, three to ST757, two to ST203 and one to ST612 (Table 2). eBURST analysis of the VREF isolates revealed four different STs (ST412, ST612, ST757 and ST203), three of which belonged to clonal complex 17; ST757 was not related to this clonal complex (Figure 2).

\section{Discussion}

E. faecium is a highly resistant nosocomial pathogen and has recently emerged as an important threat in hospitals worldwide [2]. In this study, the 12 examined VREF isolates exhibited multidrug resistance to ampicillin, amoxicillin-clavulanate, ciprofloxacin, clindamycin, chloramphenicol, streptomycin, gentamicin, rifampicin, erythromycin and teicoplanin. At HIMFG, several types of enterococcal infections in pediatric patients are commonly treated with a combination of drugs (aminoglycoside- $\beta$-lactams, such as gentamicin/ampicillin) as the first choice, while vancomycin is the second choice; vancomycin-aminoglycoside or linezolid is the third choice; and tigecycline is the fourth choice. Interestingly, $16.7 \%(2 / 12)$ of the VREF clinical isolates were also resistant to linezolid, and $67 \%(8 / 12)$ were resistant to both tetracycline and doxycycline. The emergence of high levels of resistance to the most common antienterococcal antibiotics (vancomycin) might constitute a real challenge in the treatment of these infections. In the present study, $100 \%(12 / 12)$ of the examined VREF isolates were susceptible to tigecycline and nitrofurantoin. The VREF resistance patterns observed in this study are in agreement with the findings of other authors [30,31]. However, these authors observed VREF isolates that were susceptible to linezolid and nitrofurantoin, in contrast to our data, which showed that two of the VREF isolates were resistant to linezolid. Nevertheless, the low resistance to linezolid observed in the VREF clinical isolates is in accord with data reported in other countries $[11,32]$.

Few instances of the isolation of HLAR E. faecium have been documented worldwide [22,33,34]. In this study, the examined VREF clinical isolates showed 


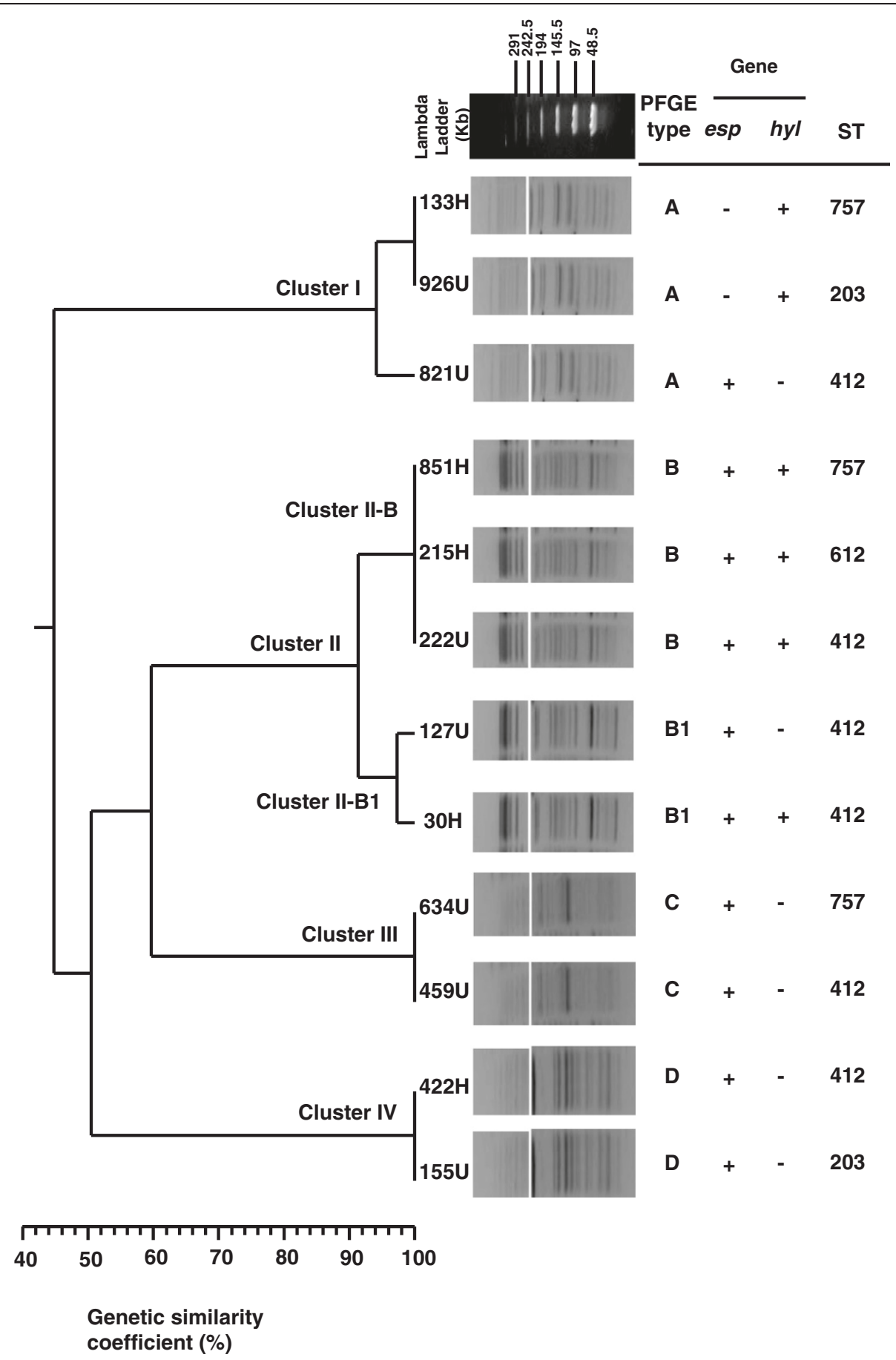

Figure 1 PFGE analysis of 12 VREF isolates recovered at HIMFG and detection of the virulence factors esp and hyl, sequence type, isolation ward and type of sample. Phylogenetic analysis was performed using the DICE coefficient in association with the UPGMA algorithm as the grouping method. The dendrogram was evaluated by obtaining the cophenetic correlation coefficient using the Mantel test, which yielded an $r$ value of 0.97769 .

HLAR to gentamicin $(500 \mu \mathrm{g} / \mathrm{ml})$, streptomycin $(1,000$ $\mu \mathrm{g} / \mathrm{ml})$ and gentamicin/streptomycin $(500 / 1,000 \mu \mathrm{g} / \mathrm{ml})$, displaying resistance values of $50 \%, 25 \%$ and $25 \%$, respectively. Treatment of severe enterococcal infection requires combined therapy to achieve a synergistic bactericidal effect [35]. However, the results obtained in cases of severe infections associated with enterococci have shown that HLAR should not be treated with combined therapy (gentamicin/ampicillin) [35]. Therefore, the treatment of HLAR E. faecium is restricted [36]. 


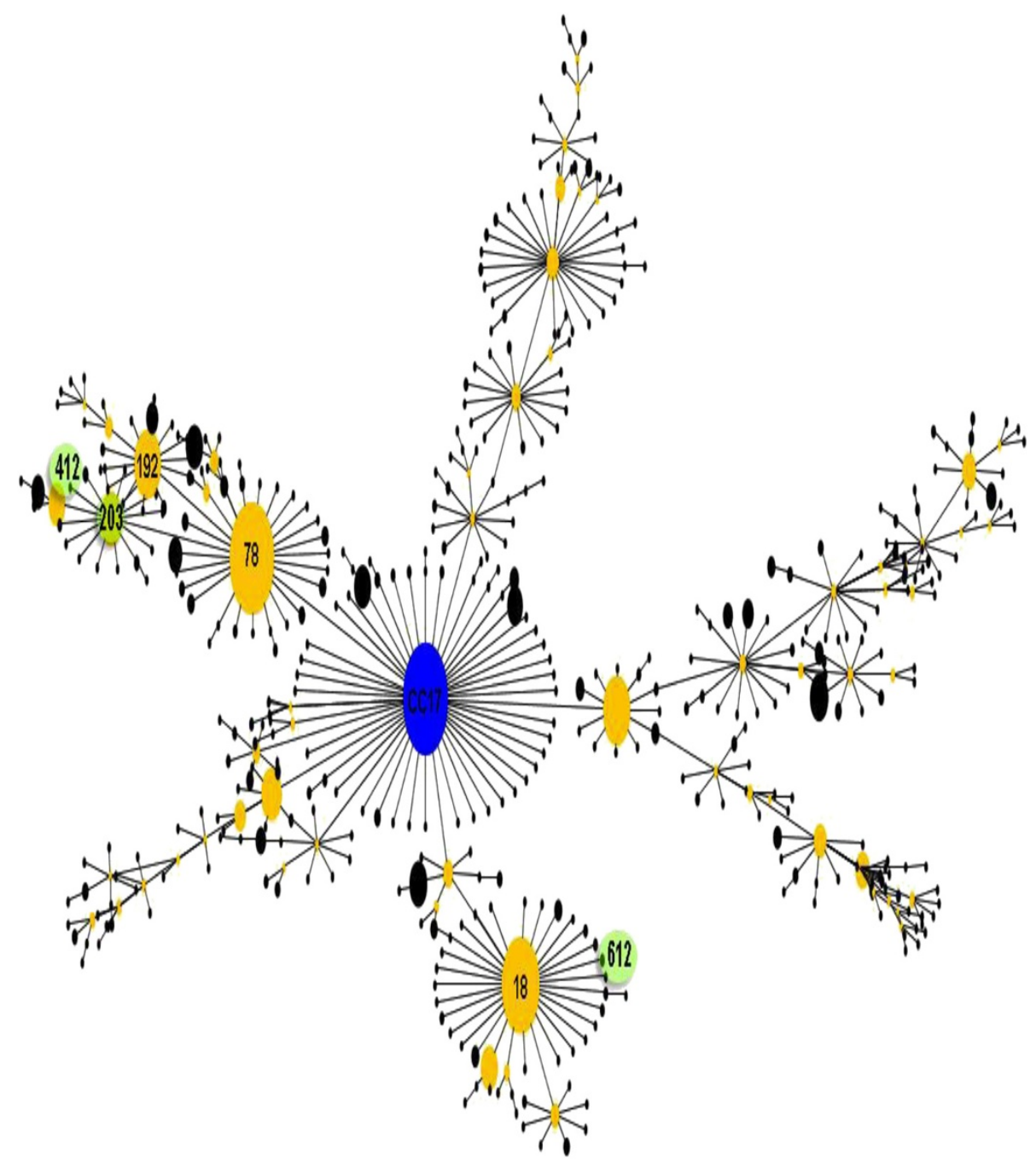

Figure 2 Clustering of MLST profiles using the eBURST database algorithm. Our profiles showed that ST412, ST612 and ST203, but not ST757, belong to clonal complex 17.

The enterococcal surface protein Esp, which is encoded by genes that appear to have been acquired and localized within a pathogenicity island, is commonly found in clinical isolates and anchors to the cell wall. This protein also affects biofilm formation and plays a role in experimental UTI and/or endocarditis models [2]. The presence of the esp gene has been associated with hospital outbreaks, although this gene is not exclusively found in epidemic strains $[19,30,37,38]$. The esp gene was detected in $83.3 \%$ of our VREF clinical isolates. In addition, the majority of $e s p^{+}$strains of E. faecium isolates were multidrug-resistant to more than three antibiotics, in accord with data reported by other researchers [39-41].

On the other hand, the $h y l$ gene was found in $50 \%$ of the VREF clinical isolates and displayed a higher prevalence compared to the prevalences of $29.8 \%(29 / 131)$ reported in isolates of $E$. faecium in the Picardy Region of France, 38\% (83/220) in isolates from the US and 3\% in European clinical isolates. However, in the United Kingdom, a $h y l$ gene prevalence of $71 \%(20 / 28)$ was observed in E. faecium isolates [14,42,43]. We believe that the differences observed in the detection rates of the $h y l$ gene are due to the region in which the samples were isolated. The rates of the occurrence of $e s p^{+} / h y l^{-}$, $e s p^{+} / h y l^{+}$and $e s p^{-} / h y l^{+}$isolates were found to be 50\% (6/ $12), 33.3 \%(4 / 12)$ and $16.7 \%(2 / 12)$, respectively, which is in accord with the findings of Vankerckhoven et al. and Rice et al. $[14,42,44]$. The VREF clinical isolates of Mexican origin in which the esp and/or hyl gene was amplified (alone or together), were resistant to more than three antibiotics; in contrast, other studies have shown a significant correlation between the presence of the esp gene and resistance to ampicillin, imipenem and ciprofloxacin $[40,41]$. 
PFGE and MLST analyses have been proposed as alternative methods for the molecular characterization of clinical isolates of E. faecium [45]. According to our PFGE analysis, the 12 VREF isolates showed a heterogeneous pattern associated with a profile of multidrug resistance to different antibiotics and the presence of the vanA gene. The data obtained through PFGE revealed four clusters (I-IV), with a low similarity of $44 \%$ being detected among the VREF isolates and therefore high diversity. Furthermore, the VREF isolates within clusters I, II-B and III showed an identical banding profile in the PFGE analysis. However, the MLST data indicated different STs due to changes in the nucleotide sequences of the analyzed housekeeping genes; these data are consistent with the findings of Poh et al. [46]. In addition, the VREF isolates within clusters II-B1 and IV displayed identical PFGE and MLST profiles, in agreement with other authors [22,33]. Nevertheless, pulsotypes from different wards showed similar multidrug resistance profiles, possibly due to horizontal genetic transference between these isolates.

MLST is an important tool for studying the molecular epidemiology of outbreaks of E. faecium and microbial population biology [44]. MLST analysis of VREF clinical isolates revealed four STs: ST203, ST412, ST612 and ST757. As previously reported, clonal complex 17 harbors various STs that have been involved in hospital outbreaks. Our results revealed two allelic profiles, ST203 and ST412, belonging to clonal complex 17 STs involved in hospital outbreaks. However, clonal complex 17 has been resolved into two different subgroups, one of which harbors ST17 and ST18, while the second harbors ST78 [47]. ST17, ST18 and ST203 are the major groups in the genetic lineage of E. faecium; they are distributed worldwide and have been associated with outbreaks $[18,48]$. ST412 was the most frequent sequence type found in the VREF isolates from HIMFG and was genetically linked to the ST78 lineage. Interestingly, ST412 has been identified worldwide and associated with outbreaks [49]. According to the eBURST analysis, ST612 showed characteristics of the STs belonging to the 18 lineage. ST757 has not been characterized within clonal complex 17. In addition, ST757 displayed resistance markers (ampicillin and quinolones), virulence genes $\left(e s p^{+}\right.$and/or $\left.h y l^{+}\right)$ and the purK 1 allele; however, it has not been associated with outbreaks. Nevertheless, this community of multidrug-resistant strains is able to infect humans and might contribute to the spreading of these bacteria in the hospital, highlighting the importance of molecular typing via MLST to identify STs involved in nosocomial outbreaks.

Recently, it was shown that MLST analysis of typified E. faecium based on selected alleles may generate misleading results due to the recombination of five alleles
(atpA, $d d l, g d h, g y d$ and pstS). As only the purk and $a d k$ alleles are located in regions where there is no predicted recombination, the results must be interpreted with care [50]. The genome of E. faecium is highly plastic due to the few existing barriers to the acquisition of foreign genetic elements [51,52]. Recent studies have provided evidence of high levels of recombination through comparative genomics analyses [51-54]. Whole-genome sequencing platforms are superior to conventional typing methods, providing an excellent tool for determining phylogenies and regions of recombination and for accurately discriminating between outbreak- and nonoutbreak-causing VREF isolates [50,55]. Thus, wholegenome sequence information, rather than data on just one or a few genes, could be used to distinguish between closely related strains.

In this study, MLST and PFGE analysis were applied for the molecular characterization of clinical VREF isolates to identify different clonal complexes with different pulsotypes that were not related to outbreaks. However, according to the results obtained through PFGE, four multidrug-resistant clones of VREF were identified at HIMFG; in addition, these VREF isolates were identified at different periods. Therefore, these data suggest that these clones have circulated endemically at HIMFG.

In the case of cluster II, the clones have evolved from cluster II-B to cluster II-B1 due to the high similarity (> 90\%) observed via PFGE analysis and based on the acquisition of three bands for B1, suggesting a mechanism of horizontal gene transfer. The results obtained in this study highlight the importance of monitoring circulating VREF isolates in different wards of this institution to efficiently control multidrug resistance and prevent outbreaks of these clones.

\section{Conclusion}

Little is known about VREF isolates in Mexican hospitals. In this study, the detected virulence genes (esp and $h y l$ ), multidrug profiles and allelic patterns were associated with clonal complex 17 VREF clinical isolates obtained from pediatric patients at HIMFG. To our knowledge, this is the first report describing clonal complex 17 VREF isolates in a tertiary care center in Mexico City.

Multidrug resistance and genetic determinants of virulence confer advantages in VREF in the colonization of their hosts. The genome of E. faecium is highly plastic, showing an ability to readily acquire genes involved in environmental persistence, colonization and virulence, favoring the selection of specific clonal complexes in a hospital environment. Therefore, the prevention and control of the propagation of nosocomial infections caused by VREF is crucial for identifying new emergent subclones that could be challenging to treat in subsequent years. 


\section{Ethics statement}

The study was reviewed and approved by the Research (Dr. Onofre Muñoz Hernández), Ethics (Dr. Amparo Faure Fontenla) and Biosecurity (Dr. Herlinda Vera Hermosillo) Committee of HIMFG, under permit numbers HIM/2011/019. After looking at the medical history of each patient, E. faecium isolates were recovered from clinical samples, and the patients were asked by the physicians in the Infectology Department of HIMFG for their permission for their samples be used in this study. Analyses of E. faecium isolates obtained from clinical samples are not considered routine studies. Informed consent was obtained from the patient for the publication of this report and any accompanying images.

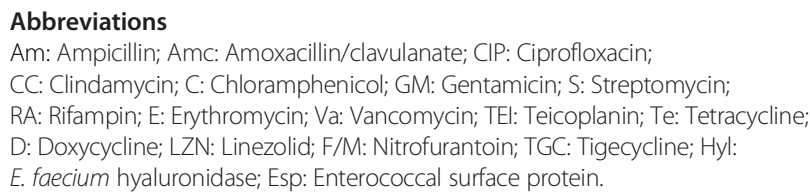

\section{Competing interests}

The authors declare that they have no competing interests.

\section{Authors' contributions}

SAO, LBD and GE performed the susceptibility pattern analysis, molecular genetics experiments and PFGE and MLST assays. SAO, ZS and ACC participated in editing the manuscript and the data analysis. VCD, CAE, BLM, $\mathrm{RHC}$ and GAJ conducted the diagnoses of the patients, interpreted data, collaborated in the collection of samples and revised the manuscript. JXC is the principal investigator and conceived the study, designed the experiments, performed data analysis and wrote the manuscript. All authors read and approved the final version.

\section{Acknowledgements}

We thank Ma. del Carmen Castellanos Cruz and Ana Karina Espinosa Mazariego for their technical assistance in this study. This work was partially supported by grants HIM/2011/019 from Federal Funds from the Hospital Infantil de México Federico Gómez, CONACyT 133451 and the Fondo Sectorial de Investigación en Salud y Seguridad Social, FOSSIS-CONACYT 2012-01-182651.

\section{Author details}

'Departamento de Infectología, Laboratorio de Bacteriología Intestinal, Hospital Infantil de México Federico Gómez, México City, DF 06720, México. ${ }^{2}$ Departamento de Salud Pública, Facultad de Medicina, Universidad Nacional Autónoma de México, Av. Insurgentes Sur s/n., México City, DF 04510, México. ${ }^{3}$ Departamento Clínico, Hospital Infantil de México Federico Gómez, México City, DF 06720, México. ${ }^{4}$ Departamento de Ecología de Agentes Patógenos, Hospital General "Dr. Manuel Gea González", Tlalpan 14080, México. ${ }^{5}$ Unidad de Investigación en Enfermedades Oncológicas, Hospital Infantil de México Federico Gómez, Dr. Márquez 162, Col. Doctores, Delegación Cuauhtémoc, México City, DF 06720, México.

Received: 12 September 2013 Accepted: 2 December 2013 Published: 11 December 2013

\section{References}

1. Top J, Willems R, Bonten M: Emergence of CC17 Enterococcus faecium: from commensal to hospital-adapted pathogen. FEMS Immunol Med Microbiol 2008, 52(3):297-308

2. Arias CA, Murray BE: The rise of the Enterococcus: beyond vancomycin resistance. Nat Rev Microbiol 2012, 10(4):266-278.

3. Grayson ML, Eliopoulos GM, Wennersten CB, Ruoff KL, De Girolami PC, Ferraro MJ, Moellering RC Jr: Increasing resistance to beta-lactam antibiotics among clinical isolates of Enterococcus faecium: a 22-year review at one institution. Antimicrob Agents Chemother 1991, 35(11):2180-2184.

4. Jones RN, Sader HS, Erwin ME, Anderson SC: Emerging multiply resistant enterococci among clinical isolates. I. Prevalence data from 97 medical center surveillance study in the United States. Enterococcus Study Group. Diagn Microbiol Infect Dis 1995, 21(2):85-93.

5. Rice LB: Emergence of vancomycin-resistant enterococci. Emerg Infect Dis 2001, 7(2):183-187.

6. Uttley $\mathrm{AH}$, Collins $\mathrm{CH}$, Naidoo J, George RC: Vancomycin-resistant enterococci. Lancet 1988, 1(8575-6):57-58.

7. Hidron Al, Edwards JR, Patel J, Horan TC, Sievert DM, Pollock DA, Fridkin SK: NHSN annual update: antimicrobial-resistant pathogens associated with healthcare-associated infections: annual summary of data reported to the national healthcare safety network at the centers for disease control and prevention, 2006-2007. Infect Control Hosp Epidemiol 2008, 29(11):996-1011.

8. Coque TM, Tomayko JF, Ricke SC, Okhyusen PC, Murray BE: Vancomycinresistant enterococci from nosocomial, community, and animal sources in the United States. Antimicrob Agents Chemother 1996, 40(11):2605-2609.

9. Rice LB: Antimicrobial resistance in gram-positive bacteria. Am J Med 2006, 119(6):S11-19-S62-70.

10. Johnson AP, Uttley AH, Woodford N, George RC: Resistance to vancomycin and teicoplanin: an emerging clinical problem. Clin Microbiol Rev 1990, 3(3):280-291.

11. Deshpande LM, Fritsche TR, Moet GJ, Biedenbach DJ, Jones RN: Antimicrobial resistance and molecular epidemiology of vancomycinresistant enterococci from North America and Europe: a report from the SENTRY antimicrobial surveillance program. Diagn Microbiol Infect Dis 2007, 58(2):163-170

12. Teng F, Kawalec M, Weinstock GM, Hryniewicz W, Murray BE: An Enterococcus faecium secreted antigen, SagA, exhibits broad-spectrum binding to extracellular matrix proteins and appears essential for E. faecium growth. Infect Immun 2003, 71(9):5033-5041.

13. Nallapareddy SR, Singh KV, Murray BE: Contribution of the collagen adhesin Acm to pathogenesis of Enterococcus faecium in experimental endocarditis. Infect Immun 2008, 76(9):4120-4128.

14. Rice LB, Carias L, Rudin S, Vael C, Goossens H, Konstabel C, Klare I, Nallapareddy SR, Huang W, Murray BE: A potential virulence gene, hylEfm, predominates in Enterococcus faecium of clinical origin. J Infect Dis 2003, 187(3):508-512.

15. Heikens E, Bonten MJ, Willems RJ: Enterococcal surface protein Esp is important for biofilm formation of Enterococcus faecium E1162. J Bacteriol 2007, 189(22):8233-8240.

16. Willems RJ, Van Schaik W: Transition of Enterococcus faecium from commensal organism to nosocomial pathogen. Future Microbio/ 2009, 4(9):1125-1135.

17. Homan WL, Tribe D, Poznanski S, Li M, Hogg G, Spalburg E, Van Embden JD, Willems RJ: Multilocus sequence typing scheme for Enterococcus faecium. J Clin Microbiol 2002, 40(6):1963-1971.

18. Willems RJ, Top J, Van Santen M, Robinson DA, Coque TM, Baquero F, Grundmann H, Bonten MJ: Global spread of vancomycin-resistant Enterococcus faecium from distinct nosocomial genetic complex. Emerg Infect Dis 2005, 11(6):821-828.

19. Leavis H, Top J, Shankar N, Borgen K, Bonten M, Van Embden J, Willems RJ: A novel putative enterococcal pathogenicity island linked to the esp virulence gene of Enterococcus faecium and associated with epidemicity. J Bacteriol 2004, 186(3):672-682

20. Bonten MJ, Willems R, Weinstein RA: Vancomycin-resistant enterococci: why are they here, and where do they come from? Lancet Infect Dis 2001, 1(5):314-325.

21. Damani A, Klapsa D, Panopoulou M, Spiliopoulou I, Pantelidi K, Malli E, Kolonitsiou F, Grapsa S, Alepopoulou E, Frantzidou F, et al: A newly described vancomycin-resistant ST412 Enterococcus faecium predominant in Greek hospitals. Eur J Clin Microbiol Infect Dis 2010, 29(3):329-331.

22. Panesso D, Reyes J, Rincon S, Diaz L, Galloway-Pena J, Zurita J, Carrillo C, Merentes A, Guzman M, Adachi JA, et al: Molecular epidemiology of vancomycin-resistant Enterococcus faecium: a prospective, multicenter study in South American hospitals. J Clin Microbio/ 2010, 48(5):1562-1569.

23. Clark NC, Cooksey RC, Hill BC, Swenson JM, Tenover FC: Characterization of glycopeptide-resistant enterococci from U.S. hospitals. Antimicrob Agents Chemother 1993, 37(11):2311-2317. 
24. Kariyama R, Mitsuhata R, Chow JW, Clewell DB, Kumon H: Simple and reliable multiplex PCR assay for surveillance isolates of vancomycinresistant enterococci. J Clin Microbio/ 2000, 38(8):3092-3095.

25. Shankar V, Baghdayan AS, Huycke MM, Lindahl G, Gilmore MS: Infectionderived Enterococcus faecalis strains are enriched in esp, a gene encoding a novel surface protein. Infect Immun 1999, 67(1):193-200.

26. Morrison D, Woodford N, Barrett SP, Sisson P, Cookson BD: DNA banding pattern polymorphism in vancomycin-resistant Enterococcus faecium and criteria for defining strains. J Clin Microbiol 1999, 37(4):1084-1091.

27. Turabelidze D, Kotetishvili M, Kreger A, Morris JG Jr, Sulakvelidze A Improved pulsed-field gel electrophoresis for typing vancomycinresistant enterococci. J Clin Microbiol 2000, 38(11):4242-4245.

28. Tenover FC, Arbeit RD, Goering RV, Mickelsen PA, Murray BE, Persing DH, Swaminathan B: Interpreting chromosomal DNA restriction patterns produced by pulsed-field gel electrophoresis: criteria for bacterial strain typing. J Clin Microbiol 1995, 33(9):2233-2239.

29. Mullane NR, Whyte P, Wall PG, Quinn T, Fanning S: Application of pulsedfield gel electrophoresis to characterise and trace the prevalence of Enterobacter sakazakii in an infant formula processing facility. Int J Food Microbiol 2007, 116(1):73-81.

30. Torres E, Perez S, Vindel A, Rodriguez-Bano J, Camba V, Villanueva R, Coque TM, Bou G: Glycopeptide-resistant Enterococcus faecium in a hospital in northern Spain. Molecular characterization and clinical epidemiology. Enferm Infecc Microbiol Clin 2009, 27(9):511-517.

31. Pourakbari B, Aghdam MK, Mahmoudi S, Ashtiani MT, Sabouni F, Movahedi Z, Alyari AE, Sadeghi RH, Mamishi S: High frequency of vancomycinresistant Enterococcus faecalis in an Iranian referral children medical hospital. Maedica 2012, 7(3):201-204.

32. Werner $G$, Klare I, Fleige $C$, Witte $W$ : Increasing rates of vancomycin resistance among Enterococcus faecium isolated from German hospitals between 2004 and 2006 are due to wide clonal dissemination of vancomycin-resistant enterococci and horizontal spread of vanA clusters. Int J Med Microbiol 2008, 298(5-6):515-527.

33. Weng PL, Ramli R, Shamsudin MN, Cheah YK, Hamat RA: High Genetic Diversity of Enterococcus faecium and Enterococcus faecalis Clinical Isolates by Pulsed-Field Gel Electrophoresis and Multilocus Sequence Typing from a Hospital in Malaysia. Biomed Res Int 2013, 2013:938937.

34. Araoka $\mathrm{H}$, Kimura M, Yoneyama A: A surveillance of high-level gentamicinresistant enterococcal bacteremia. J Infect Chemother 2011, 17(3):433-434.

35. Murray BE: Vancomycin-resistant enterococcal infections. N Engl J Med 2000, 342(10):710-721.

36. Watanabe S, Kobayashi N, Quinones D, Nagashima S, Uehara N, Watanabe $\mathrm{N}$ : Genetic diversity of enterococci harboring the high-level gentamicin resistance gene aac(6')-le-aph(2")-la or aph(2")-le in a Japanese hospital. Microb Drug Resist 2009, 15(3):185-194.

37. Leavis HL, Willems RJ, Top J, Spalburg E, Mascini EM, Fluit AC, Hoepelman A, De Neeling AJ, Bonten MJ: Epidemic and nonepidemic multidrugresistant Enterococcus faecium. Emerg Infect Dis 2003, 9(9):1108-1115.

38. Coque TM, Willems R, Canton R, Del Campo R, Baquero F: High occurrence of esp among ampicillin-resistant and vancomycin-susceptible Enterococcus faecium clones from hospitalized patients. J Antimicrob Chemother 2002, 50(6):1035-1038.

39. Eaton TJ, Gasson MJ: A variant enterococcal surface protein Esp(fm) in Enterococcus faecium; distribution among food, commensal, medical, and environmental isolates. FEMS Microbiol Lett 2002, 216(2):269-275.

40. Dupre I, Zanetti S, Schito AM, Fadda G, Sechi LA: Incidence of virulence determinants in clinical Enterococcus faecium and Enterococcus faecalis isolates collected in Sardinia (Italy). J Med Microbiol 2003, 52(Pt 6):491-498.

41. Billstrom H, Lund B, Sullivan A, Nord CE: Virulence and antimicrobial resistance in clinical Enterococcus faecium. Int J Antimicrob Agents 2008, 32(5):374-377

42. Vankerckhoven V, Van Autgaerden T, Vael C, Lammens C, Chapelle S, Rossi $R$, Jabes D, Goossens $H$ : Development of a multiplex PCR for the detection of asa1, gelE, cylA, esp, and hyl genes in enterococci and survey for virulence determinants among European hospital isolates of Enterococcus faecium. J Clin Microbiol 2004, 42(10):4473-4479.

43. Biendo M, Adjide C, Castelain S, Belmekki M, Rousseau F, Slama M, Ganry O, Schmit JL, Eb F: Molecular characterization of glycopeptide-resistant enterococci from hospitals of the picardy region (france). Int J Microbiol 2010, 2010:150464
44. Cha JO, Jung YH, Lee HR, Yoo Jl, Lee YS: Comparison of genetic epidemiology of vancomycin-resistant Enterococcus faecium isolates from humans and poultry. J Med Microbiol 2012, 61(Pt 8):1121-1128.

45. Kuriyama T, Williams DW, Patel M, Lewis MA, Jenkins LE, Hill DW, Hosein IK: Molecular characterization of clinical and environmental isolates of vancomycin-resistant Enterococcus faecium and Enterococcus faecalis from a teaching hospital in Wales. J Med Microbiol 2003, 52(Pt 9):821-827.

46. Poh LW, Rukman AW, Cheah YK, Norital Z, Nazri AM, Mariana NS: Vancomycin-resistant Enterococcus faecium of multi locus sequence type 18 in Malaysia. Med J Malaysia 2012, 67(6):639-640.

47. Willems RJ, Top J, Van Schaik W, Leavis H, Bonten M, Siren J, Hanage WP, Corander J: Restricted gene flow among hospital subpopulations of Enterococcus faecium. MBio 2012, 3(4):e00151-00112.

48. Werner G, Coque TM, Hammerum AM, Hope R, Hryniewicz W, Johnson A, Klare I, Kristinsson KG, Leclercq R, Lester $\mathrm{CH}$, et al: Emergence and spread of vancomycin resistance among enterococci in Europe. Euro Surveill 2008, 13:47.

49. Freitas AR, Novais C, Ruiz-Garbajosa P, Coque TM, Peixe L: Dispersion of multidrug-resistant Enterococcus faecium isolates belonging to major clonal complexes in different Portuguese settings. App/ Environ Microbiol 2009, 75(14):4904-4908.

50. Howden BP, Holt KE, Lam MM, Seemann T, Ballard S, Coombs GW, Tong SY, Grayson ML, Johnson PD, Stinear TP: Genomic insights to control the emergence of vancomycin-resistant enterococci. MBio 2013, 4:4

51. Galloway-Pena J, Roh JH, Latorre M, Qin X, Murray BE: Genomic and SNP analyses demonstrate a distant separation of the hospital and community-associated clades of Enterococcus faecium. PLoS One 2012, 7(1):e30187.

52. Palmer KL, Godfrey P, Griggs A, Kos VN, Zucker J, Desjardins C, Cerqueira G, Gevers D, Walker S, Wortman J, et al: Comparative genomics of enterococci: variation in Enterococcus faecalis, clade structure in $E$. faecium, and defining characteristics of E. gallinarum and E. casseliflavus. MBio 2012, 3(1):e00318-00311.

53. De Been M, Van Schaik W, Cheng L, Corander J, Willems RJ: Recent recombination events in the core genome are associated with adaptive evolution in Enterococcus faecium. Genome Biol Evol 2013, 5(8):1524-1535.

54. Van Schaik W, Top J, Riley DR, Boekhorst J, Vrijenhoek JE, Schapendonk CM, Hendrickx AP, Nijman IJ, Bonten MJ, Tettelin H, et al: Pyrosequencingbased comparative genome analysis of the nosocomial pathogen Enterococcus faecium and identification of a large transferable pathogenicity island. BMC Genomics 2010, 11:239.

55. Reuter S, Ellington MJ, Cartwright EJ, Koser CU, Torok ME, Gouliouris T, Harris SR, Brown NM, Holden MT, Quail M, et al: Rapid bacterial whole-genome sequencing to enhance diagnostic and public health microbiology. JAMA Intern Med 2013, 173(15):1397-1404.

doi:10.1186/1471-2180-13-291

Cite this article as: Ochoa et al:: Molecular analysis and distribution of multidrug-resistant Enterococcus faecium isolates belonging to clonal complex 17 in a tertiary care center in Mexico City. BMC Microbiology 2013 13:291.

\section{Submit your next manuscript to BioMed Central and take full advantage of:}

- Convenient online submission

- Thorough peer review

- No space constraints or color figure charges

- Immediate publication on acceptance

- Inclusion in PubMed, CAS, Scopus and Google Scholar

- Research which is freely available for redistribution 